\title{
CLINICAL AND RADIOLOGICAL PROFILE OF COPD PATIENTS ATTENDING TERTIARY CARE CENTRE
}

\author{
Ramakrishna Rachakonda1, Suryakumari Beri², Kalyankumar P. V3
}

1 Professor and HOD, Department of Pulmonology, Katuri Medical College, Guntur, Andhra Pradesh.

2 Post Graduate, Department of Pulmonology, Katuri Medical College, Guntur.

${ }^{3}$ Associate Professor, Department of Pulmonology, Katuri Medical College, Guntur.

\section{ABSTRACT}

We have studied a total of 103 COPD patients based on spirometry. We excluded patients with a history of Tuberculosis. Majority of them were in the moderate obstruction group of FEV1 between $50 \%$ and $80 \%$ predicted. All of them had FEV1/FVC of 0.7 or less. Mean age of the patients was 57.6 \pm . Male:Female ratio was 73:30. All except two male patients were smokers. Eighteen out of thirty female patients were passive smokers. Majority in our study were agricultural workers. Majority of the symptomatic COPD patients had a smoking index of more than 100. Predominant symptom in our study was shortness of breath. Only a third of the patients showed clinical signs of wheeze and crepitations. Predominant number of patients presented with signs of emphysema. Chest X-ray showed Emphysema in 86\%, Chronic Bronchitis in 31\%, Cardiomegaly in 14.5\% and Enlarged Pulmonary Artery in 13.5\%.

\section{KEYWORDS}

COPD (Chronic Obstructive Pulmonary Disease), DALY (Disability Adjusted Life Years), FEV1, FVC, ECG, Cardiomegaly, Chronic Bronchitis, Emphysema.

HOW TO CITE THIS ARTICLE: Rachakonda R, Beri S, Kalyankumar PV. Clinical and radiological profile of COPD patients attending tertiary care centre. J. Evolution Med. Dent. Sci. 2016;5(21):1124-1127, DOI: 10.14260/jemds/2016/261

\section{INTRODUCTION}

Chronic Obstructive Pulmonary Disease (COPD) is a major cause of chronic morbidity and mortality throughout the world. COPD is 4 th leading cause of death in the world. ${ }^{1}$ and is going to become the $3^{\text {rd }}$ leading cause of death by 2030 worldwide. ${ }^{2}$ Globally, the COPD burden is projected to increase in coming decades because of continued exposure to COPD risk factors and aging of the population. ${ }^{3}$ More than 3 million people died of COPD in 2012, which is equal to $6 \%$ of all deaths globally that year and according to projections COPD will be the 7th leading cause of Disability Adjusted Life Years (DALY) lost worldwide by 2030, thus accounting for enormous social and economic burden worldwide.

\section{AIMS AND OBJECTIVES}

1. To Study the Clinical and Radiological Profile in COPD patients; 2 . To correlate these findings with severity of the disease.

\section{MATERIAL AND METHODS}

\section{Source of the Data}

The present study was conducted in Department of Pulmonary Medicine in KMCH Hospital, Guntur; 103 COPD patients who were attending OP were included in study. The study period was October 2014 to September 2015.

\section{Design}

Cross Sectional study.

\section{Inclusion Criteria}

Adult males and females aged more than 35 years with a history suggestive of chronic obstructive pulmonary airway disease were selected at random from the Outpatient Department of KMCH, Guntur, for the present study.

Financial or Other, Competing Interest: None.

Submission 28-01-2016, Peer Review 24-02-2016,

Acceptance 29-02-2016, Published 14-03-2016.

Corresponding Author:

Dr. Ramakrishna Rachakonda,

Sanjeevani Hospital, A1

Ramkuteer Majestic, 3/13, Brodipet,

Guntur-522002, Andhra Pradesh.

E-mail: ramakrishna45@yahoo.co.in

DOI: $10.14260 /$ jemds $/ 2016 / 261$
The diagnosis of chronic obstructive pulmonary disease is made by symptoms in the history and confirmed by physical examination, radiographic examination and lung spirometry for airway obstruction by spiroanalyzer.

The patients who are diagnosed as having chronic obstructive pulmonary disease as per GOLD guidelines with FEV1/FVC $<70 \%$ are further divided into 4 groups.

Group I: Patients who fulfil the above criteria and belong to mild COPD based on predicted FEV1 (80\% and above of pred value) after bronchodilator inhalation.

Group II: Patients who fulfil the above criteria and belong to moderate COPD based on predicted FEV1 (50-80\% of pred value).

Group III: Patients who fulfil the above criteria and belong to severe COPD based on predicted FEV1 (30-50\% of pred value).

Group IV: Patients belonging to very severe group having FEV1 values of $<30 \%$ predicted after bronchodilation.

\section{Exclusion Criteria}

1. Cases excluded from the present study are primary diagnosis of bronchial asthma, known sleep apnoea, lung cancer, known left ventricular dysfunction, other debilitating cancers, poorly controlled hypertension, significant valvular disease and known coronary artery diseases (Angina, ischaemic changes in resting ECG or documented history of myocardial infarction).

2. Patients with active pulmonary Koch's and those with history of Pulmonary Koch's.

Patients were subjected to clinical, radiological and spirometric evaluation.

\section{RESULTS AND OBSERVATIONS}

The present study included 103 patients with stable chronic obstructive pulmonary disease, attending medical outpatient department in Katuri Medical College and Hospital, Guntur.

\section{Age Distribution in COPD Patients}

The age of the patients being studied ranged between $40 \mathrm{yrs}$. to 81 yrs. The moderate COPD group ranged from 45 yrs. to 81 yrs. 
The ages in severe COPD group were 45 yrs. to 63 yrs. and in very severe COPD group was 50 to 62 yrs.

\begin{tabular}{|c|c|c|c|}
\hline $\begin{array}{c}\text { Age } \\
\text { Distribution }\end{array}$ & $\begin{array}{c}\text { Moderate } \\
\text { COPD }\end{array}$ & $\begin{array}{c}\text { Severe } \\
\text { COPD }\end{array}$ & $\begin{array}{c}\text { Very Severe } \\
\text { COPD }\end{array}$ \\
\hline $40-50$ & 15 & 2 & - \\
\hline $51-60$ & 41 & 3 & 1 \\
\hline $61-70$ & 28 & - & - \\
\hline $71-80$ & 5 & - & - \\
\hline$>80$ & 1 & & \\
\hline Mean age & $57.60+8.898$ & & \\
\hline $\begin{array}{c}\text { Standard } \\
\text { deviation }\end{array}$ & 8.898 & Table 1: Age Distribution \\
\hline \multicolumn{3}{|c|}{} \\
\hline
\end{tabular}

Majority of moderate and severe stage COPD patients belonged to 40 to 70 yrs. age group.

Majority of very severe stage COPD patients belonged to 51-70 yrs. age.

\begin{tabular}{|c|c|c|c|}
\hline $\begin{array}{c}\text { Sex } \\
\text { Distribution }\end{array}$ & $\begin{array}{c}\text { Moderate } \\
\text { COPD }\end{array}$ & $\begin{array}{c}\text { Severe } \\
\text { COPD }\end{array}$ & $\begin{array}{c}\text { Very Severe } \\
\text { COPD }\end{array}$ \\
\hline Males & 65 & 3 & 1 \\
\hline Female & 25 & 2 & 1 \\
\hline \multicolumn{3}{|c|}{ Table 2: Sex Distribution in COPD Patients } \\
\hline
\end{tabular}

In present study $72.10 \%$ were males, $30.90 \%$ were females.

Most of patients were farmers, most of females were daily wage labourers

\begin{tabular}{|c|c|c|c|}
\hline Occupation & $\begin{array}{c}\text { Moderate } \\
\text { COPD }\end{array}$ & $\begin{array}{c}\text { Severe } \\
\text { COPD }\end{array}$ & $\begin{array}{c}\text { V. Severe } \\
\text { COPD }\end{array}$ \\
\hline Farmers & 64 & 3 & - \\
\hline $\begin{array}{c}\text { Daily wage } \\
\text { labourers }\end{array}$ & 24 & 2 & 2 \\
\hline Drivers & 2 & & \\
\hline \multicolumn{3}{|c|}{ Table 3: Occupation History } \\
\hline
\end{tabular}

Most of patients were active smokers (69.01\%), Passive smoking history present in females $(\mathbf{2 8 . 8 4 \% )}$

\begin{tabular}{|c|c|c|c|}
\hline $\begin{array}{c}\text { Smoking } \\
\text { History }\end{array}$ & $\begin{array}{c}\text { Moderate } \\
\text { COPD }\end{array}$ & $\begin{array}{c}\text { Severe } \\
\text { COPD }\end{array}$ & $\begin{array}{c}\text { V. Severe } \\
\text { COPD }\end{array}$ \\
\hline $\begin{array}{c}\text { Active } \\
\text { smokers }\end{array}$ & 68 & 3 & 0 \\
\hline $\begin{array}{c}\text { Passive } \\
\text { smokers }\end{array}$ & 16 & 2 & 2 \\
\hline \multicolumn{4}{|c|}{ Table 4: Smoking History } \\
\hline
\end{tabular}

All male patients except 2 had a history of smoking. Out of 30 females in the study, 18 females are exposed to biomass fuel or passive smoking. Among the rest 12 female and 2 male patients who did not smoke, no definite cause could be established and hence environmental factors, for example air pollution and passive smoking may be considered as the possible aetiology for COPD in them.

All the symptomatic patients in our study have exposure to tobacco or biological fuel for more than 15 years.

Among the 71 active smokers, 29 (40.84\%) had a smoking index of less than 100; $33(46.47 \%)$ patients have a smoking index between 100 and 200; 9 patients (12.67\%) gave smoking index of $>300$. Smoking index is calculated as the number of pieces smoked, $\mathrm{X}$ no. of years of smoking.

\begin{tabular}{|c|c|c|c|}
\hline Symptoms & $\begin{array}{c}\text { Moderate } \\
\text { COPD }\end{array}$ & $\begin{array}{c}\text { Severe } \\
\text { COPD }\end{array}$ & $\begin{array}{c}\text { V. Severe } \\
\text { COPD }\end{array}$ \\
\hline Cough & 4 & & \\
\hline $\begin{array}{c}\text { Shortness of } \\
\text { breath }\end{array}$ & 42 & & \\
\hline Cough, SOB & 44 & 5 & 2 \\
\hline \multicolumn{3}{|c|}{ Table 5: Symptoms-Analysis } \\
\hline
\end{tabular}

\begin{tabular}{|c|c|c|}
\hline $\begin{array}{c}\text { Physical } \\
\text { Signs }\end{array}$ & $\begin{array}{c}\text { Number of Patients } \\
\text { (n-103) }\end{array}$ & Percentage \\
\hline Pedal oedema & 23 & $22.33 \%$ \\
\hline Raised JVP & 12 & $14.5 \%$ \\
\hline \multicolumn{3}{|c|}{ Table 6: Physical Signs } \\
\hline
\end{tabular}

$22.33 \%$ have pedal oedema, $14.50 \%$ have raised JVP in present study.

\section{Respiratory System Signs}

\begin{tabular}{|c|c|c|}
\hline RS Findings & $\begin{array}{c}\text { Number of } \\
\text { Patients }\end{array}$ & Percentage \\
\hline Rhonchi & 33 & $32.03 \%$ \\
\hline Crepitations & 21 & $20.3 \%$ \\
\hline $\begin{array}{c}\text { Rhonchi, } \\
\text { Crepitations }\end{array}$ & 8 & $7.77 \%$ \\
\hline \multicolumn{2}{|c|}{ Table 7: Respiratory Symptoms and Signs } \\
\hline
\end{tabular}

$32.03 \%$ had Rhonchi, $20.30 \%$ having Crepitations in present study. Rhonchi and crepitations were seen in $7.77 \%$. A good number of patients do not have clinical signs on clinical examination, but chest X-ray and PFT showed abnormalities.

\begin{tabular}{|c|c|c|}
\hline $\begin{array}{c}\text { Chest X-ray } \\
\text { Findings }\end{array}$ & $\begin{array}{c}\text { Number of } \\
\text { Patients (n=103) }\end{array}$ & Percentage \\
\hline Emphysema & 64 & $62.13 \%$ \\
\hline Chronic bronchitis & 19 & $18.44 \%$ \\
\hline $\begin{array}{c}\text { Emphysema, ch. } \\
\text { bronchitis }\end{array}$ & 14 & $13.5 \%$ \\
\hline Cardiomegaly & 15 & $14.56 \%$ \\
\hline $\begin{array}{c}\text { Enlarged pulmonary } \\
\text { artery }\end{array}$ & 14 & $13.5 \%$ \\
\hline \multicolumn{2}{|c|}{ Normal X-ray } & 6 \\
\hline \multicolumn{2}{|c|}{ Table 8: Chest X-ray Findings } \\
\hline
\end{tabular}

\section{X-ray Findings}

Most of patients (62.13\%) had features of Emphysema, Chronic Bronchitis (18.44\%), Both (13.5\%). Pulmonary Arterial Enlargement in 13.5\% and Cardiomegaly in 14.56\%.

\begin{tabular}{|c|c|c|}
\hline $\begin{array}{c}\text { Severity of } \\
\text { COPD(FEV1) }\end{array}$ & $\begin{array}{c}\text { Number of } \\
\text { Patients(n=103) }\end{array}$ & Percentage \\
\hline Mild (0.8-2.12 L/min) & 06 & $5.82 \%$ \\
\hline $\begin{array}{c}\text { Moderate (0.6-1.43 } \\
\text { L/min) }\end{array}$ & 90 & $87.37 \%$ \\
\hline $\begin{array}{c}\text { Severe (0.3-0.9 L/ } \\
\text { min) }\end{array}$ & 5 & $4.85 \%$ \\
\hline $\begin{array}{c}\text { V. Severe (0.3-0.21 } \\
\text { L/min) }\end{array}$ & 2 & $1.94 \%$ \\
\hline \multicolumn{2}{|c|}{ Table 9: Spirometry Results } \\
\hline
\end{tabular}

Most of patients: (85.49\%) belonged to moderate COPD group.

\section{DISCUSSION}

Majority of moderate and severe stage COPD pts. belonged to 40 to 70 yrs. age group. Majority of very severe stage COPD pts. belonged to 51-70 yrs. age group. Thus COPD patients in our 
study belonged to the bread earning age, middle and old age and that could have caused considerable impact on the financial status of the family. This is complicated by increased treatment as well as hospitalization charges for the older COPD patients.

Our study correlates with other studies like Chetan et al. ${ }^{4}$ Jain et al. ${ }^{5}$ Vikram B Vikhe et al. ${ }^{6}$ in age distribution as COPD is disease of older age group.

In the present study, out of 103 patients 73 (75.19\%) were males and $30(30.99 \%)$ females. The male:female ratio of this study was 2.4:1. COPD is a male dominant disease, the high prevalence in males which is due to higher prevalence of smoking in this gender and smoking is the most common risk factor. Population based studies of COPD have shown an average prevalence ratio of $6: 1$. The increase in women COPD patients in our study is probably attributable to increased passive smoking among the rural women of this area and also to exposure to bio fuel.

\section{Comparison of Sex Distribution}

COPD is predominantly male disease. Different studies showed different male:female ratios. Chetanrathi et al. (74:26).4 Radhakrishnan et al. (84:16). ${ }^{7}$ Satish Kinagi et al. (54:45). ${ }^{8}$ and the present study showed a male:female ratio of 73:30. Mohapatra et al. ${ }^{9}$ a ratio of 70:03 during acute exacerbation of COPD, but their average age of presentation to the hospital was $60 \pm 9$. In India exposure to biomass fuel and passive smoking has increased COPD among women. ${ }^{9}$

Thus, all the studies indicated a higher incidence of COPD in males.

\section{Table: Occupation Distribution Comparison}

In present study most of them were farmers (68\%), small proportion were daily wage labourers $(30 \%)$ and two were bus drivers (1.94\%). Satish Kinagi et al. ${ }^{8}$ had lower percentage of farmers suffering from COPD. But in our study, predominant number of patients are from rural set up working as farmers and agricultural labourers.

\section{Smoking History}

All male patients except 2 had a history of smoking of $5 \mathrm{yrs}$. or more; 18 females in the study are exposed to biomass fuel due to firewood cooking and passive smoking. Among the 30 females, 12 female and 2 male patients who did not smoke, no definite cause could be established and hence environmental factors for example air pollution and passive smoking may be considered as the possible aetiology for COPD in them. We have an interesting observation in our study that passive smokers constitute nearly $20 \%$ of the symptomatic COPD patients stressing the importance of passive smoking as contributing to symptomatic COPD.

The favoured mode of smoking was cigarettes. Out of 103 patients included in the study, 29 people had smoking index of less than 100, 33 people had smoking index of 200-300 and 9 patients had smoking index of $>300$ and 2 patients did not smoke at all and none of the females were active smokers.

Our study revealed that a Smoking index of 100 and above is significant parameter for causation of symptomatic COPD. Many other studies have taken PACK YEARS to assess the impact and few studies took the SMOKING INDEX like Lokendra Dave et al.10,11 and present study. In Lokendra Dave et al. study most of symptomatic COPD patients had smoking index of 600-900 high smoking index increased cardiovascular risk factors among patients of COPD. In present study most of symptomatic COPD patients had smoking index of 200-300.

We have taken Smoking index in our study because Tobacco is consumed in our area in multiple forms of smoking tobacco namely Chutta (The tobacco leaf), the beedi, (Tobacco powder bound in Tendu leaf), cigarettes (Both filter and nonfilter). Tobacco is also consumed orally along with Betel nut. Chetanrati et al. ${ }^{4}$ had $61 \%$ smokers and $39 \%$ nonsmokers and Lokendra Dave et al. in their study showed $87 \%$ smokers. ${ }^{10,11}$

RR Hegde et al. ${ }^{12}$ In their study found that severity of dyspnoea increased with smoking index. Our study showed that predominantly symptomatic patients were found to have a smoking index of more than 100. MS Bharthwal et al. ${ }^{13}$ showed that early detection of COPD by spirometry in smokers more than 40 years of age, having a smoking index more than 200 , is likely to reduce overall burden of disease.

\section{Symptoms Analysis Comparison}

In the present study, breathlessness is the most common symptom which is seen in almost $98 \%$ of the patients. Followed by cough and expectoration indicating these symptoms are present in chronic bronchitis and emphysema subtypes. Cough was a more significant features in other similar studies like those of Satish Kinagi et al. ${ }^{8}$ Agarwal et al. ${ }^{14}$ J Jain et al. ${ }^{15}$ studies. Present study differs with other studies in symptoms; in other studies, cough is predominant symptom, in present study dyspnoea is predominant symptom. The difference in our study is due to avoidance of all cases of COPD with a history of Tuberculosis.

\section{Physical Signs}

Raised JVP was found in $12.36 \%$ of our patients. The signs of right heart failure were significantly more common in patients with severe obstruction. Our study suggests that raised JVP can be considered as a significant sign of severe COPD. In our study pedal oedema was found $23.69 \%$. In comparison Satish Kinagi et al. ${ }^{8}$ showed a JVP raise of $19.04 \%$ and Pedal oedema of $20.8 \%$. Agarwal et al. ${ }^{14}$ found 22 and $38 \%$ of JVP raise and Pedal oedema in their study. Jain et al. 15 found JVP raise in 33\% and Pedal oedema of $50 \%$ in their study. Our study showed lesser prevalence of raised JVP and Pedal oedema probably because of the fact that majority of our patients are stable and belong to moderate FEV1 obstruction. Nevertheless, raised JVP and Pedal oedema are taken as serious signs of COPD and indicate right heart dysfunction. Though in our study significant number of patients are seen with moderate obstruction, a good number of them had raised JVP and pedal oedema.

\section{Respiratory System Signs}

Diminished respiratory movements, diminished breath sounds and expiratory rhonchi were most common signs elicited on respiratory examination. These signs in combination with smoking history might suggest a pointer towards diagnosing COPD. Wheeze and rales were found 33.33 and $26.01 \%$ of patients in our study respectively.

Agarwal et al.14 had $61 \%$ wheeze and $0 \%$ rales. In present study, less percentage of wheeze and rhonchi when compared to other studies because only stable COPD patients were included in study. Patients can develop significant obstruction without much clinical signs signifying that we must actively examine the patients in high risk group with spirometry for early identification of COPD. 


\section{Radiological Examination}

In present study, out of 103 (100\%) patients studied 75 (86.52\%) patients had features suggestive of emphysema, chronic bronchitis (31.93\%) on chest X-ray. Cardiomegaly was significantly more common in patients with severe COPD group. Cardiomegaly is observed in $15.45 \%$ of patients and enlarged pulmonary artery on Chest X-ray seen in $11.35 \%$ of patients, which might warrant us to go for ECG and ECHO in ruling out PAH and Cor pulmonale. Agarwal et al. ${ }^{14}$ had $84 \%$ and $68 \%$ of emphysema and chronic bronchitis respectively. Cardiomegaly in their study was comparable to our study. Vikram Vicky et al. ${ }^{6}$ had lower prevalence of Emphysema and higher prevalence of chronic bronchitis. They had higher prevalence of pulmonary artery enlargement and cardiomegaly.

\section{Pulmonary Function Tests}

The PFT parameters namely FEV1/FVC $>0.7$ were excluded from study. Patients were divided into mild, moderate, severe, very severe COPD according to guidelines. Out of 103 patients, $85(85.49 \%)$ belonged to moderate group COPD, study results and observations significant in moderate COPD patients. In our study, Majority of the patients (87.38\%) belonged to moderate obstruction group. Similar observations were made in the studies of Chetan Rathi et al. ${ }^{4}$ Jain et al. ${ }^{15}$

\section{SUMMARY AND CONCLUSIONS}

COPD is a fairly common debilitating disease in India. It is more common in males and in the 5th and 6th decade (Mean age 57.2). Most of the symptomatic patients were in moderate COPD group at presentation. We have excluded patients with history of Tuberculosis. Female COPD patients constituted nearly $25 \%$. Though majority of them are non-smokers, a majority of them had passive smoking giving rise to the importance of passive smoking and biological fuel exposure as equally important causes of COPD among females. COPD is a major problem among the agrarian rural community in India. Most of patients had FEV1 between $50 \%-80 \%$ of moderate obstruction. As significant symptoms are seen only in a third of the patients, we must actively look for COPD with spirometry in high risk patients for early identification.

Our study suggests that it is necessary to identify smoker COPD patients with smoking index less than $<100$ as majority of symptomatic COPD patients fall in group of smoking index of more than 100. Early identification of smokers with a smoking index of less than 100 and adapting measures to stop smoking can prevent long-term complications of pulmonary hypertension and cor pulmonale.

Patients of COPD presented with raised JVP $(11.65 \%$ or 12 patients) and pedal oedema (22.33\%, 23 patients) even among the moderate group. We observed that patients developed raised JVP and right heart failure even when the FEV1 is moderate.

Chest X-ray in our study showed predominant emphysema in $75 \%$ of our patients. Enlarged pulmonary artery and cardiomegaly were seen in a significant number of patients stressing the importance of chest X-ray in identifying pulmonary heart disease.

\section{REFERENCES}

1. Suzanne Hurd. The impact of COPD on drug health worldwide, epidemiology and incidence. Chest 2000;117:1S-4S.

2. John J Reilly Jr, Edwin K, Silverman. Chronic obstructive pulmonary disease. Chapter 242. In: Dennis L Kasper, Eugene Braunwald, editors. Harrison's principles of internal medicine, 16th edition, 2005;2:1547-1554.

3. Lopez AD, Shibuya K, Rao C, et al. Chronic obstructive pulmonary disease: current burden and future projections. Eur respire J 2006;27(2):397-412.

4. Chetan Rathi, Anil Wanjari, Sourya Acharya. "Pulmonary hypertension in mild-moderate COPD: an early link." Journal of Evidence based Medicine and Healthcare 2015;2(42):7330-7340.

5. Jain NK, Thakkar MS, Jain N, et al. Chronic obstructive pulmonary disease: does gender really matter? Lung India 2011;28(4):258-262.

6. Vikram B Vikhe, Prakash S Shende, Rahul S Patil, et al. Cardiovascular complications in chronic obstructive pulmonary disease with reference to 2D echocardiography findings. Natl J Med Res 2013;3(4):385-388.

7. Radha Krishnan D, Barama Srihari. A study on the severity of right ventricular dysfunction in correlation with the severity of lung dysfunction in chronic obstructive pulmonary disease patients-COPD. ISSN: 2377-6196, Global science publishing group USA. The American Journal of science and medical 2015;1(1):112119.

8. Sathish kinagi, Sharan Patil, Sayeeda Afiya. Analysis of chronic obstructive pulmonary disease with clinical parameters, ECG, and Echo. Journal of Evolution of Medical and Dental Sciences 2014;3(57):12864-12880. DOI:10.14260/jemds/2014/3710.

9. Prasanta Raghab Mohapatra, Ashok Kumar Janmeja. Factors for hospitalisation in AE-COPD. The Indian Journal of Chest Diseases \& Allied Sciences 2010;52:203206.

10. Dave L, Rajoriya V, Dubey TN, et al. Evaluation of BODE index as a predictor of pulmonary hypertension in COPD patients. Ann Int Med Den Res 2015;1(3):213-17.

11. Dave L, Dwivedi P, Srivastava N, et al. A study of cardiovascular manifestations of COPD. Int J Res Health Sci 2014;2(3):812-7. Available from: http://www.ijrhs.com/issues.php?

12. Hegde RR, Phadtare JM, Ramraje NN. Study of smoking index, spirometry and severity of chronic lung disease. Indian Journal of Basic \& Applied Medical Research 2013;8(2):1043-1046.

13. Barthwal MS, Singh S. Early detection of chronic obstructive pulmonary disease in asymptomatic smokers using spirometry. Journal of the association of physicians of india 2014;62:238-42.

14. Agarwal KC, Deepak Singh, Patil Shital, et al. Cardiovascular alterations in COPD what hurts the patient the most? Journal of Medical Education \& Research ISSN 2249-9660. 2013;3(1). 